\title{
Technological change
}

\author{
Mike Cooley $^{1}$
}

Published online: 9 June 2016

(C) Springer-Verlag London 2016

Those charged with implementing technological and organisational change are frequently moved by the loftiest of motives. Thus in 1642, when Pascal invented the first truly mechanical calculating machine, he declared "I submit to the public a small machine of my own invention by means of which you may, without any effort, perform all the operations of arithmetic relieved of the work which so often fatigued your spirit when you were working with the counter and the pen".

However, technology is a double-edged matter. It is rooted in Taylorism whose inventor once said "In my system, the workman is told precisely what he is to do and how he is to do it, and any improvement he makes upon the instructions given to him is fatal to success." Taylor called his system 'Scientific Management'.

The motivations here are often quite obvious and quoted in adverts from the late 1970s "People are trouble, but machines obey" and "Robots don't strike." The range of applications of such technology is an overriding motivation.

What is sad about this approach is that it squanders one of society's most precious assets which is the skill, ingenuity and creativity of its people. In this context the (late) design engineer and professor of Control Engineering at UMIST Howard Rosenbrock, wrote that computer control displays a loss of nerve and a misunderstanding as to how design and development proceeds. He pointed out that

Mike Cooley

m.cooley@btconnect.com

1 AI \& Society Advisory Board, 95 Sussex Place, Slough SL11NN, UK
"Engineering is an art rather than a science and in saying that I imply a higher rather than a lower status."

It is unfortunate indeed that in this historical turning point, when intellectual work is being subjected to forms of Taylorism, we still find a terrible wastage of human skill and ingenuity. However, there is still time for a human-centred approach to become possible which will create a symbiotic relationship. Human-centred systems could provide a much richer and more productive environment for work, but the systems continue to be reductionist and an opportunity for something much more fulfilling is currently ignored.

There are some professions and systems which are making a positive use of robotic-type tools. For example, these telechiric devices are deployed by surgeons in keyhole surgery and by pilots who train in flight simulators. In each case the operator is in control and their skills and abilities are enhanced. However, there is no guarantee that this will remain the practice for long.

We leave the last word to the founder of cybernetics Norbert Wiener who once cautioned "Although machines are theoretically subject to human criticism, such criticism may be ineffective until long after it is relevant."

We've been warned!

\section{Further reading}

The University as a factory. New Scientist 24th June 1976.

Mental Therbligs. New Scientist 20th March 1975.

T. Lupton (Ed). Human Factors IFS Publications Ltd UK 1986. ISBN 0-948507-22-5.

K.S. Gill Ed. Human Machine Symbiosis: The Foundations of Human-centred Systems Design. Springer 1996. ISBN 3-540-76024-5. 
Curmudgeon Corner Curmudgeon Corner is a short opinionated column on trends in technology, arts, science and society, commenting on issues of concern to the research community and wider society. Whilst the drive for super-human intelligence promotes potential benefits to wider society, it also raises deep concerns of existential risk, thereby highlighting the need for an ongoing conversation between technology and society. At the core of Curmudgeon concern is the question: What is it to be human in the age of the AI machine? -Editor. 